\title{
Visual analyses of end of injection liquid structures and the behaviour of nozzle surface-bound fuel in a direct injection diesel engine
}

Dan Sykes, Guillaume de Sercey, Cyril Crua

University of Brighton, UK

Martin Gold, Richard Pearson

BP International Ltd.

Copyright () 2019 Society of Automotive Engineers, Inc.

\section{CITATION}

Sykes D, de Sercey G, Gold M, Pearson R, Crua C. (2019) Visual analyses of end of injection liquid structures and the behaviour of nozzle surface-bound fuel in a direct injection diesel engine. SAE Technical Paper 2019-01-0059 https://doi.org/10.4271/2019-01-0059

\section{ABSTRACT}

For efficiency, the majority of modern diesel engines implement multiple injection strategies, increasing the frequency of transient injection phases and thus, end of injection (EOI) events. Recent advances in diagnostic techniques have identified several EOI phenomena pertinent to nozzle surface wetting as a precursor for deposit formation and a potential contributor towards pollutant emissions. To investigate the underlying processes, highspeed optical measurements at the microscopic scale were performed inside a motored diesel engine under low load/idling conditions. Visualisation of the injector nozzle surface and near nozzle region permitted an indepth analysis of the post-injection phenomena and the behaviour of fuel films on the nozzle surface when the engine is not fired. Inspection of the high-speed video data enabled an interpretation of the fluid dynamics leading to surface wetting, elucidating the mechanisms of deposition and spreading. As the needle re-seated, the abrupt pressure drop inhibited atomisation. Large, slow moving, liquid structures were released into the cylinder with the capability of impinging on nearby surfaces, creating localised fuel rich regions, or escaping through the exhaust and contributing towards un-burnt hydrocarbon emissions. Large ligaments remained attached to the nozzle, with some fluid subsequently breaking away while the remaining fuel adhering the nozzle retracted back causing surface wetting. The EOI event was succeeded by further surface wetting due to the expansion of orificetrapped gas dislodging nozzle-residing fuel that then overspilled onto the external surface. The drop in in-cylinder pressure elicited bubbling within the surface-bound fuel, further increasing the films spreading rate. The resulting bubble agglomerations collapsed in large chain reactions, projecting more fuel into the cylinder. Finally, as the intake valves closed, high velocity intake air was diverted towards the nozzle removing the remaining surface-bound fuel. As a result, a large volume of fuel was released into the combustion chamber after the EOI causing deposits on nearby surfaces or getting released through the exhaust where it would contribute towards un-burnt hydrocarbon emissions. It is likely that the anticipated increase in in-cylinder pressure and temperature if the engine was fired would either reduce the time-scale of these event or completely inhibit them. However, understanding the behaviour of the surface-bound fuel within this environment will aid designs that control surface wetting, thus inhibiting nozzle coking with the capacity to control internal deposits.

\section{INTRODUCTION}

Contending with the progressive introduction of vehicle emission regulations over the last 30 years [1] has been a demanding challenge for the automotive industry, and one that will continue for the foreseeable future. It is well established that the efficiency of an engine and the pollutant emissions are primarily governed by the air-fuel mixing process [2]. Modifications to the in-cylinder components, in particular the fuel injection equipment (FIE), have led to enhanced control over the flow rate profile [3] and a refined spray atomisation, thereby improving power delivery with a cleaner combustion. These modifications result in increased in-cylinder temperatures, gas pressures and injection pressures (with commercial common rail sys- 
tem reaching pressures of over $300 \mathrm{MPa}$ [4]), leading to harsher conditions in the immediate vicinity of the injector nozzle, thought to accelerate the formation of injector deposits [5, 6]. Higher internal injector temperatures are reached in modern injectors due to the increased number of smaller orifices, smaller sac sizes and larger actuator control chambers. This promotes fuel degradation potentially leading to further deposit build up and increased UHC emissions [7, 8].

Injector deposits can be classified into two major groups; internal diesel injector deposits (IDIDs) which includes control valve, needle, sack and orifice channel deposits, and coking which refers only to external deposits situated around the orifice. Many researchers have found it difficult to decouple their effects as they are appear to occur in unison however, a direct mechanism between the formation of each has not yet been established. The accumulation of both IIDs and coking has been associated with reduced power delivery, engine durability and the production of pollutants [9-13]. Severe deposits may even lead to engine failure [14].

Orifice fouling reduces the flow rate through increased frictional forces caused by the rough deposit surface, promoting turbulence in the emerging spray $[15,16]$. The deposit thickness is normally small, typically in the region of 0.5 to $4 \mu \mathrm{m}$ (up to $10 \mu \mathrm{m}$ at the outlet) [15-18], yet they can lead to a considerable impact on the discharge rate due to the small orifice sizes (of around $100 \mu \mathrm{m}$ ) in modern injectors [19]. The influence of roughness on the inorifice cavitation [20] may also have a considerable effect on the spray characteristics [21]. IIDs and in-orifice deposits alter the precisely designed internal geometry of the nozzle thereby diverting the internal flow and cavitational behaviour from its ideal, compromising the subsequent atomisation [17]. Needle deposits may result in misfire and even injector failure due to seizure or sticking to the valve seat $[14,22]$. Coking was reported long before IIDs since they tend to be much larger and their detection does not require dissection of the injector [23]. A great deal of behaviour resulting from IIDs was originally attributed to coking when in fact coking has very little effect on the spray dynamics [7]. Modern injectors use common rail pressures large enough to knock away any coking that protrudes into the jet. However, Li et al. shown that an increase in orifice length, which is a possible consequence of coking, reduces the spray plume angle and exit velocity, yet this was demonstrated on a gasoline direct injection (GDI) injector at a lower injection pressures $[20,24]$.

In addition to the more recent issue of injector deposits, transient injection phases, in particular at the EOI, are believed to be a persistent sources of emissions [25]. During the end of injection, the complex fluid flow inside the nozzle and orifices results in the discharge of large, slow and deformed liquid structures as the spray collapses [25]. This leads to two problems. First of all, the liquid often lands on near-nozzle surface where it is then exposed to the high pressures and temperatures inside the cylinder $[26,27]$. The locally rich regions of surface-bound fuel may undergo incomplete combustion or degradation leading to the production of deposit precursors. This is particularly true if the combustion flame front contacts the surface-bound fluid $[26,28]$. It is likely that this process impacts on the initial formation of carbonaceous fouling in and around the injector tip. Secondly, the large, slowmoving droplets that were ejected may not be atomized sufficiently to undergo complete evaporation [26, 29], thus producing unwanted combustion by-products. There is the potential for these droplets to be drawn through the exhaust valves, directly contributing to the UHC emissions. Increased use of split injection strategies increases the time spent by the spray within the transient regime. This increases the occurrence of liquid structures associated with the EOI and the related problems with emission and deposits. As such, the end of injection has recently attracted considerable efforts to characterise and explain the observed phenomena [30-33].

Whilst there are many unexplored fluid dynamic processes occurring in and around the injector nozzle at the macroscopic scale [33], our investigation is focused on the nozzle wetting processes that occur on the nozzle surface at the microscopic scale, as the cycle progresses. Our previous work confirmed that fuel would deposit and spread on the surface of the injector nozzle through both the impingement of fuel droplets and the overspill of nozzle-trapped liquid fuel $[26,27]$. The investigations were performed on a 2-stroke reciprocating rapid compression machine (RRCM), therefore the 4-stroke optical diesel engine utilised here provides further validation of the conclusions previously drawn and introduces the interactions of realistic in-cylinder gas flow.

The main objective of the present article is to evaluate the relative importance of post injection phenomena while relating them to the in-cylinder and in-nozzle flow dynamics. A technique to obtain high speed microscopic visualisation of the injector surface is presented and unfolds a story following surface-bound fuel behaviour throughout a 4-stroke cycle. Elucidation of the underlying mechanisms is provided through analyses of the in-cylinder conditions in conjunction with comparisons to external research. The release of large liquid structures into the cylinder was observed and nozzle surface wetting through ligament splitting was evident. For this valve covered orifice (VCO) type nozzle, a considerable volume of fuel was discharged onto the surface after the dribble event, frequently interrupted by the expulsion of orifice-trapped vapour pockets. Bubbling of the surface bound fuel led to the projection of large slow moving liquid structures into the cylinder, visibly drawn towards the exhaust valves. Fuel resided on the nozzle tip until the end of the intake stroke when the closing intake valve diverted the intake air towards the nozzle tip, removing the remaining fuel. 


\section{METHODOLOGY}

The investigation was conducted using a single cylinder 4-stroke optical diesel engine. It was converted from a 4-cylinder production PUMA engine with a compression ratio of 14. The $86 \mathrm{~mm}$ bore and stroke direct injection (DI) engine was motored and used an external compressor for forced induction ( $0.131 \mathrm{MPa}$ absolute inlet pressure in the present study), in conjunction with critical flow Venturi nozzles to maintain a constant intake air flow rate. The in-cylinder air motion was controlled by a swirl valve integrated into the intake manifold that split the airflow between the two intake valves at a variable ratio. The experiment was performed at maximum swirl (swirl coefficient of 4.12) which meant all of the air was channelled through one intake valve, inducing a radially imbalanced pressure leading to a rotational airflow. Coolant was pumped around a water jacket encasing the cylinder and flowed through the head via pressurised ducts. Since all of the experiments were carried out under non-reactive conditions, the primary purpose of the coolant system was to heat the engine to a stable temperature of $84^{\circ} \mathrm{C}$ prior to injection. An oil temperature of $96^{\circ} \mathrm{C}$ was maintained for the same reason. The crank was rotated at $1000 \mathrm{rpm}$, representative of idling conditions, by a Westinghouse $30 \mathrm{~kW}$ dynamometer. Fuel delivery was performed by a common rail system composed of a Bosch $\mathrm{CP} 1 \mathrm{H}$ high pressure pump (rated at $160 \mathrm{MPa}$ ), a Delphi DFI 1.3, 7-hole, VCO-type injector (Figure 1) and a vacuum Venturi used to achieve appropriate depression on the return line.

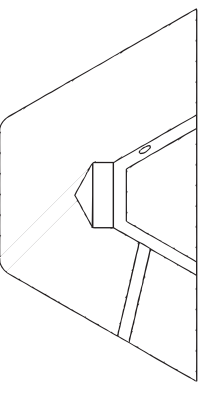

SECTION A-A

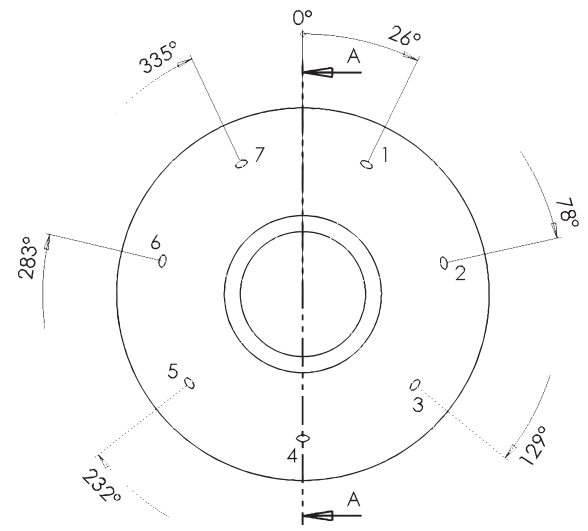

Figure 1: Approximated geometry of the Delphi VCO injector nozzle at mid-needle lift. The orifices are labelled clockwise from 12 o'clock to be used as a reference in the results section.

The test bed was instrumented with temperature and pressure sensors throughout the air, oil, coolant and fuel systems, as well as an optical encoder with a resolution of 0.5 crank angle degrees (CAD). An in-cylinder Kistler pressure sensor (with an uncertainty of $0.2 \%$ ) provided precise, high speed data acquisition of the in-cylinder pressure sampled at a rate of 2 readings per crank angle. The in-cylinder gas temperature was simulated using the manifold temperature, pressure and in-cylinder pressure in combination with the general gas equations. The test bed was controlled via an in-house LabVIEW interface.

For high speed direct imaging of the injector nozzle surface a bow-ditch optical design was used (Figure 2). The design consisted of a transparent fused silica bowl mounted onto an extended piston, permitting the placement of an optical mirror directly below the bowl. The mirror was mounted at 45 degrees to the cylinder, thereby reflecting the view of the injector into the horizontal plane to be captured by a Phantom V12 high speed camera $(10,000 \mathrm{fps}$ at $704 \times 704$ pixels $)$. The camera was fitted with an infinity K2 Distamax long distance microscope, mounted with its frontal lens within the extended piston to reduce the working distance, thus increasing the magnification. The set-up enabled visualisation of all orifices simultaneously with a scale factor of $6.94 \mu \mathrm{m} / \mathrm{pixel}$, labelled clockwise from 12 o'clock on Figure 1.

Table 1: Operating conditions, hardware parameters \& characteristics.

\begin{tabular}{rr}
\hline Parameter & Value \\
\hline Engine speed & $1,000 \mathrm{rpm}$ \\
Compression ratio & 14 \\
Injector & Delphi, DFI 1.3 \\
Nozzle type & VCO \\
Number of orifices & 7 \\
Orifice diameter & $135 \mu \mathrm{m}$ \\
Start of Injection angle & $-18 \mathrm{CAD}$ \\
Injection pulse duration & $600 \mu \mathrm{s}$ \\
Fuel & EN590 ref. Diesel \\
Inlet gas pressure & $0.131 \mathrm{MPa}$ \\
Injection pressure & $20 \mathrm{MPa}$ \\
In-cylinder swirl factor & 4.12 \\
Stroke & 4 \\
\hline
\end{tabular}

Table 2: Imaging equipment specification. The value given for the field of view does not account for the piston bowl surface curvature.

\begin{tabular}{|c|c|}
\hline Parameter & Value \\
\hline Camera & Phantom V12.1 \\
\hline Frame exposure time & $98 \mu \mathrm{s}$ \\
\hline Frame rate & $10,000 \mathrm{fps}$ \\
\hline Scale factor & $6.94 \mu \mathrm{m}$ per pixel \\
\hline Frame resolution & $752 \times 752$ pixels $^{2}$ \\
\hline Field of view & $5.22 \times 5.22 \mathrm{~mm}^{2}$ \\
\hline Laser Pulse duration & $10 \mu \mathrm{s}(\mathrm{FWHM})$ \\
\hline Laser Pulse energy & $4 \mathrm{~mJ}$ \\
\hline
\end{tabular}

To illuminate the injector and fuel, a high-speed copper vapour laser was employed operating at $511 / 579 \mathrm{~nm}$ ( $30 \mathrm{~W}$ power and $6 \mathrm{~mJ}$ pulse energy). The emitted beam was delivered via an optical fibre onto a curved fused silica window mounted on the engine. Between -30 and $30 \mathrm{CAD}$, the beam was transmitted through both the window and the edge of the piston bowl (Figure 2), creating 
further scattering and better illumination of orifices 1,4 and 7 . The optical equipment and mounts did not contact the test bed to minimise vibrations. The figure shows the piston at top dead centre (TDC) resulting in beam transmission through both the window and bowl prior to beam scattering throughout the optical chamber, illuminating the injector (Figure 2). Between \pm 24 to $30 \mathrm{CAD}$, the motion of the piston passing into the beam generated large variations in illumination, subsequently stabilising between -24 to 24 CAD. Consequently, an injection timing of $-18 \mathrm{CAD}$ was chosen for the increased luminescent stability and uniformity during the main injection event and the EOI phenomena (-14.4 CAD onwards). Furthermore, a $-18 C A D$ injection timing is representative of idling conditions for an engine of this size.

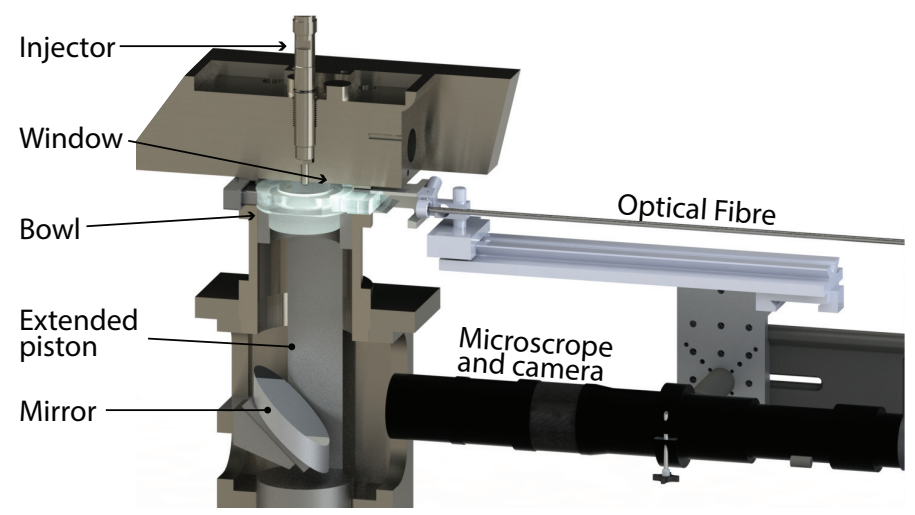

Figure 2: 3D diagram of the engine cylinder and optical equipment with the primary components labelled. Several components have been cross-sectioned for enhanced visualisation of the internal components and the beam path.

Twenty eight videos were recorded, all depicting one full cycle. The first 14 videos were recorded without pressurising the injector in order to obtain a reference for the illumination and identify any near nozzle phenomena independent of the presence of fuel. The other 14 videos were recorded at the exact same conditions with the injector pressurised to 200 bar and an electronic injection pulse width of $600 \mu \mathrm{s}$. The injector was triggered once every 8 cycles to improve the fuel scavenging and reduce fouling of the optical accesses. The skip-firing in combination with the low in-cylinder pressures and temperatures inhibited autoignition, thereby preventing sooting of the optical surfaces. Hence, the peak in-cylinder pressures and temperatures were $2.8 \mathrm{MPa}$ and $440 \mathrm{~K}$ respectively.

\section{RESULTS AND DISCUSSION}

A qualitative analysis of the high speed video data is presented, complemented by the recorded sensor data and simulated data. Several major near-nozzle and nozzlebound phenomena were identified during the injector needle descent, seating, and post injection with a high repeatability between both videos and orifices. Their analyses provides valuable insights into the mechanisms dictating surface-bound fuel behaviour between injections and their relationship with the in-cylinder and in-nozzle condi- tions. The images presented state their timing with reference to the start of injection. They refer to the start of the electronic pulse rather than the initial time that the fuel leaves the nozzle. Figure 3 gives the average in-cylinder pressure every 5CAD over 301 cycles, overlaid with the valve lift. The standard deviation is plotted above the incylinder pressure (ICP) figure giving a maximum spread of around 0.01 MPa just after top dead centre (ATDC). An ICP trace is presented with each set of images highlighting the engine timing and the relevant in-cylinder conditions.

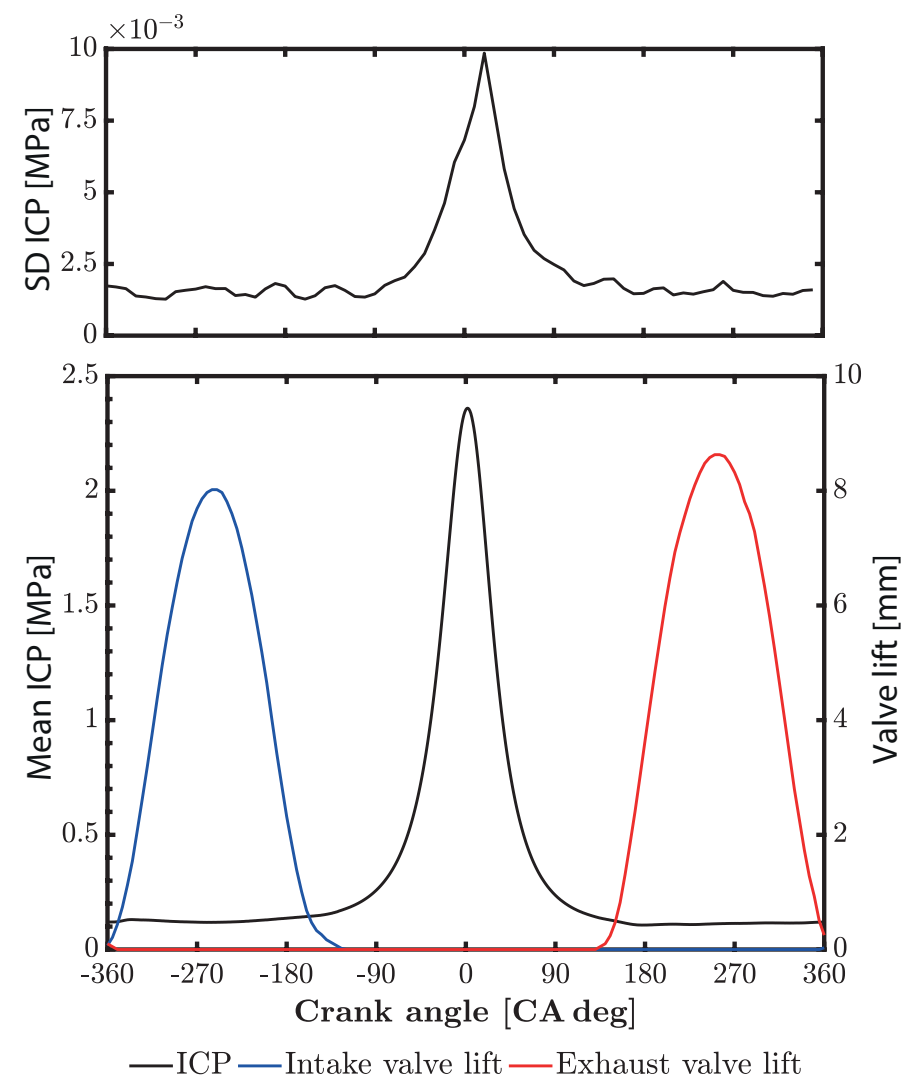

Figure 3: The average pressure measured by an incylinder pressure sensor. The standard deviation for each point is given above. The valve lift is also plotted, showing intake opening and closing times of 355 and -120 CAD ATDC respectively with exhaust valve opening and closing at 130 and -350 CAD ATDC respectively.

The electronic trigger for the injection was at 18CAD before top dead centre (BTDC) inducing the release of 7 analogous spray plumes with a high repeatability between cycles. Their dispersion angle was around $11^{\circ}$ with a small variation between orifices resulting from interactions with the swirling in-cylinder gas flow. Due to the relatively short injection duration and low injection pressure, spray stability only persisted for $100-200 \mu \mathrm{s}$, identified by the reduced dispersion angle. As the focus of this article is the transient fuel behaviour occurring post injection, no analysis was performed on this part of the videos, thus the spray angle and penetration length was not measured. 


\section{THE DRIBBLE EVENT}

At 14.4 CAD BTDC the falling edge of the injector pulse triggered the needle's descent back to its seat causing a progressive restriction to the internal flow. It took between 300 and $400 \mu s$ until any significant changes to the spray plume were evident due to the flow's inertia and the hydraulic delay (Figure 5A). Frictional forces around the flow boundaries and the sudden drop in internal nozzle pressure proceeded to dissipate the inertia, hindering the atomisation. The dispersion angle decreased and the plumes formed large uninterrupted liquid columns, encompassed by detached droplets, much larger than those observed during the main injection event (Figure 5B). The helical characteristics of the plumes from orifices $1,2,5$ and 7 gave indication of a swirling breakup mechanism, yet full confirmation of this behaviour was not possible from only 2 dimensional images. However, similar behaviour was also reported by Lockett et al. [34] using optically accessible injector nozzles in a static atmospheric rig, in which the behaviour was attributed to vortex flow within the nozzle.
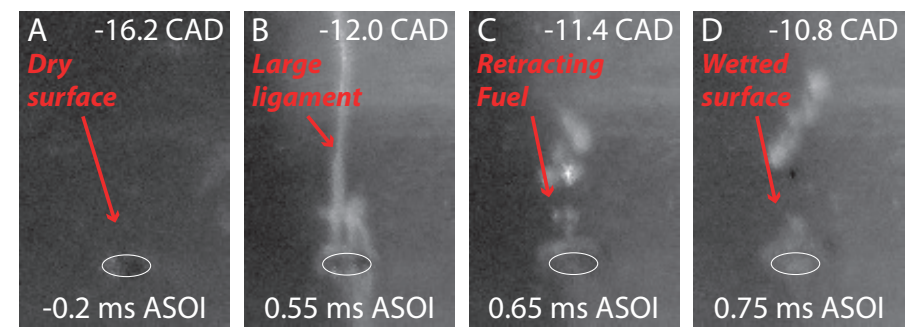

Figure 4: The breakup of an EOI ligament leaving a small volume of fuel adhering to the nozzle surface. The orifice location is highlighted by a white ellipse which is slightly displaced between frames due to engine vibrations and refraction through the in-cylinder gas. The timing is given at the bottom of the images with each image chronological labelled with a letter. The principal behaviour depicted by each image is highlighted by the red text.

The size of the liquid structures increased further as the plumes either contracted into long thin ligaments, maintaining their attachment to the orifice (Figure $5 \mathrm{C}$, orifice $1,4,5,6$ and 7 ), or underwent instant breakup into large droplets and ligaments (Figure 5C, orifices 2 and 3 ). The diameter of the thin ligaments continually decreased as the surface tension overcame the internal cohesive forces, causing them to repeatedly split into shorter structures until a stable size was reached. The release of these fuel structures is likely to create localised fuel rich regions that undergo incomplete combustion. In both cases the fluid structures tore away from the fuel immediate to the nozzle between 11.4 and 10.8 CAD BTDC $(0.5$ to $0.6 \mathrm{~ms}$ after start of injection ASOI) leaving a small quantity of fuel adhering to the surface. The residual fuel retracted back to the nozzle creating a film that covered the orifice and the surrounding surface. The angle of incident light on the injector surface and the small volume of fuel deposited meant identification of this phenomena was difficult around some orifices, however evidence of the phenomena was found in almost all cases (Figures 4 and 5).
The phenomena was also observed by Moon et al. [32] using $\mathrm{x}$-ray phase contrast imaging at similar injection parameters within a static, atmospheric pressure rig. They provided a time-frame of the events occurring during the dribble event analogous to that observed in the present work, indicating that the differences in in-cylinder pressure and temperature are not a dominating factor. Kirsch et al. [35] also described this surface wetting mechanism and demonstrated the thinning of ligaments contacting the nozzle due to increased surface tension forces in conjunction with surface adhesion, leading to ligament splitting.

Previous work in a similar test-rig gave evidence of EOI surface wetting due to large droplets moving back towards the nozzle surface and impinging, referred to as splashback [26]. This process was not observed in the present study, possibly due to the contraction of the spray plume as the flow became restricted. The increasing dispersion angle of the EOI sprays observed in the previous study may have increased the likelihood of splash-back by increasing the susceptibility of spray to gas-flow interactions and reducing the distance between the fuel and nozzle.
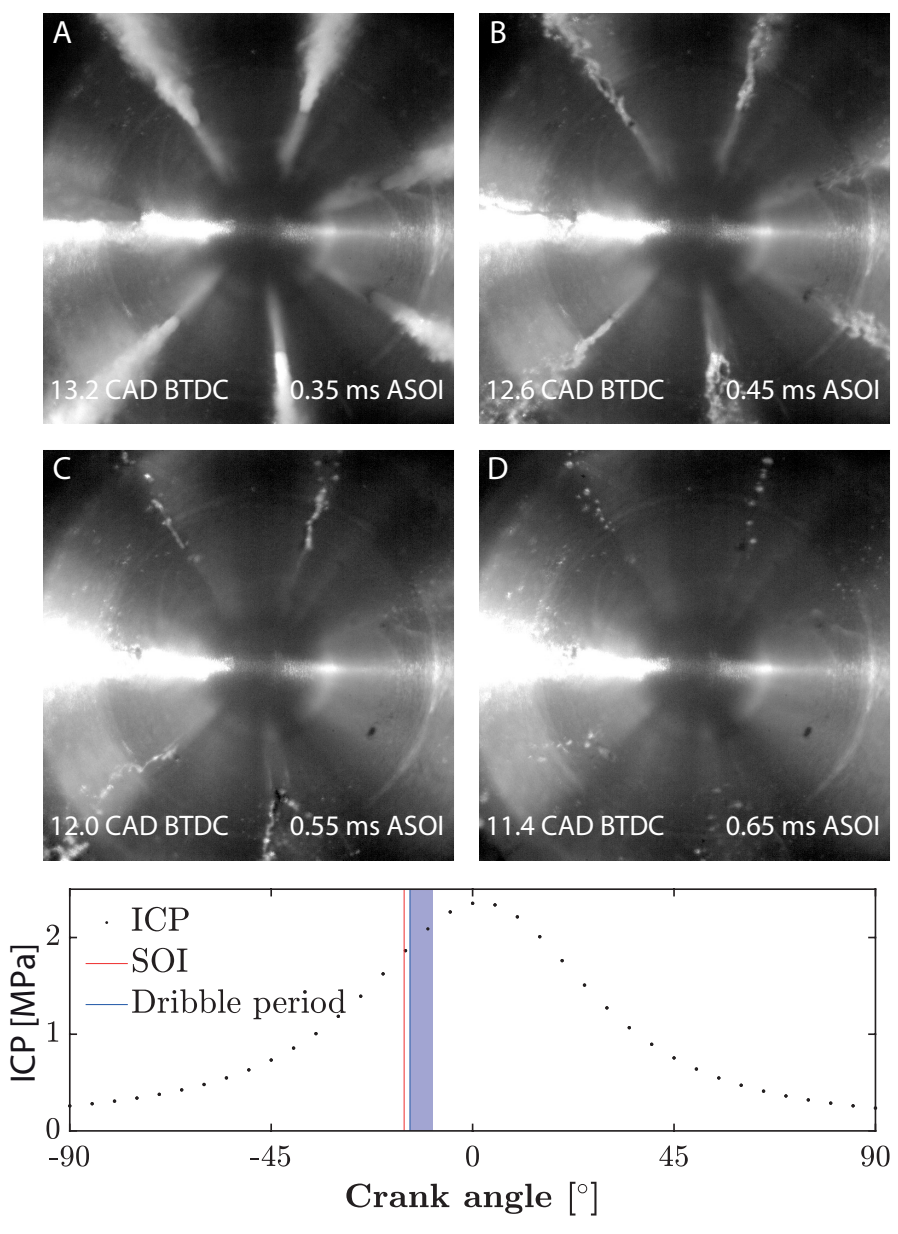

Figure 5: The injector nozzle surface and near-nozzle region throughout the dribble event. Each image is labelled chronologically from A-D and the timing is given in the bottom corners. Below the images the average pressure trace between -90 and 90 CAD is given, highlighting the SOI with a solid vertical line and the dribble period with a shaded region. 


\section{THE EXPANSION STROKE}

At 15CAD after top dead centre (ATDC) fuel spilled out from the nozzle orifices onto the external surface (Figure 6A). Red ovals are manually traced around the coverage areas and show a clear differences between the orifices at this timing. The timing of each image in Figure 6 was selected to bring attention to a specific event and thus the temporal differences between the images is not equal. As the cylinder pressure dropped during expansion, the rate of overspill increased causing substantially more wetting than that previously observed during the dribble event. The overspilling fuel was frequently interrupted by the expulsion of vapour pockets suggesting that the fuel was dislodged through the expansion of the orifice-trapped gas. Equalisation between the fuel pressure in the orifice and cylinder pressure would collapse any cavitation bubbles formed in the injector and flashboiling is unlikely under these conditions. Hence, the orifice-trapped gas must arise from gas ingestion, fuel vaporisation or the precipitation of gasses dissolved through supersaturation in the common rail system. Any saturated gases would be compelled to precipitate out of the fuel due to the in-nozzle pressure drop during needle seating, shown to be as low as $1 \mathrm{~Pa}$ [36]. A large in-nozzle pressure drop would significantly reduce the saturation temperature, increasing the likelihood of in-nozzle boiling. Several recent articles have also demonstrated the presence of nozzle-trapped gas after the main injection event in single hole sac injectors through both experimental and computational methods $[32,36]$. They concluded that the ambient gas enters the sac through the orifice during ligament to nozzle detachment. However, the conditions investigated did not account for dissolved gases. The flow's inertia at the end of the injection event causes its continual expulsion from the orifice after the needle has seated. The internal cavities previously occupied by the fuel are no longer refilled by fuel from the injector and therefore must be filled through either ingestion of ambient gas or the expansion of gas that is already inside the injector nozzle.

Before bubbles began to form in the overspilling fuel, the fuel reflected significantly more light than the fuel film residing on the nozzle during the intake stroke (Figure 6A and Figure 9). Therefore the higher pixel intensities of the fuel film during the expansion stroke is not due to the angle of incident light reflecting from the fuel film. This indicates that there is additional refraction and reflection from fluid interfaces due to vapour contained within the fuel prior to it exiting the nozzle. At 45 CAD ATDC, bubbles present on the nozzle surface were large enough to distinguish the fuel-vapour interfaces encapsulating the bubbles (Figure 6B). Their size increased at a rate similar to the in-cylinder pressure drop causing the wetted area to enlarge. Coalescence in the direction of the orifice resulted in larger bubbles at the centre of the agglomerations. The stability of a bubble is inversely proportional to its radius and when a bubble reaches a critical size the surface tension ceases to maintain the pressure gradient across its boundary, resulting in its collapse. The first signs of bubble collapse were observed around $100 \mathrm{CAD}$ ATDC (20 ms ASOI, between Figures 6C and 6D) typically from bubbles at the centre of the agglomerations. Occasionally the resulting pressure wave elicited the collapse of some large neighbouring bubbles, however, the majority of bubbles within the agglomerations were preserved (as shown in Figure 6D). There are some significant changes to this event that are anticipated if the engine was fired rather than motored, described at the end of the subsection 'The exhaust stroke' below.
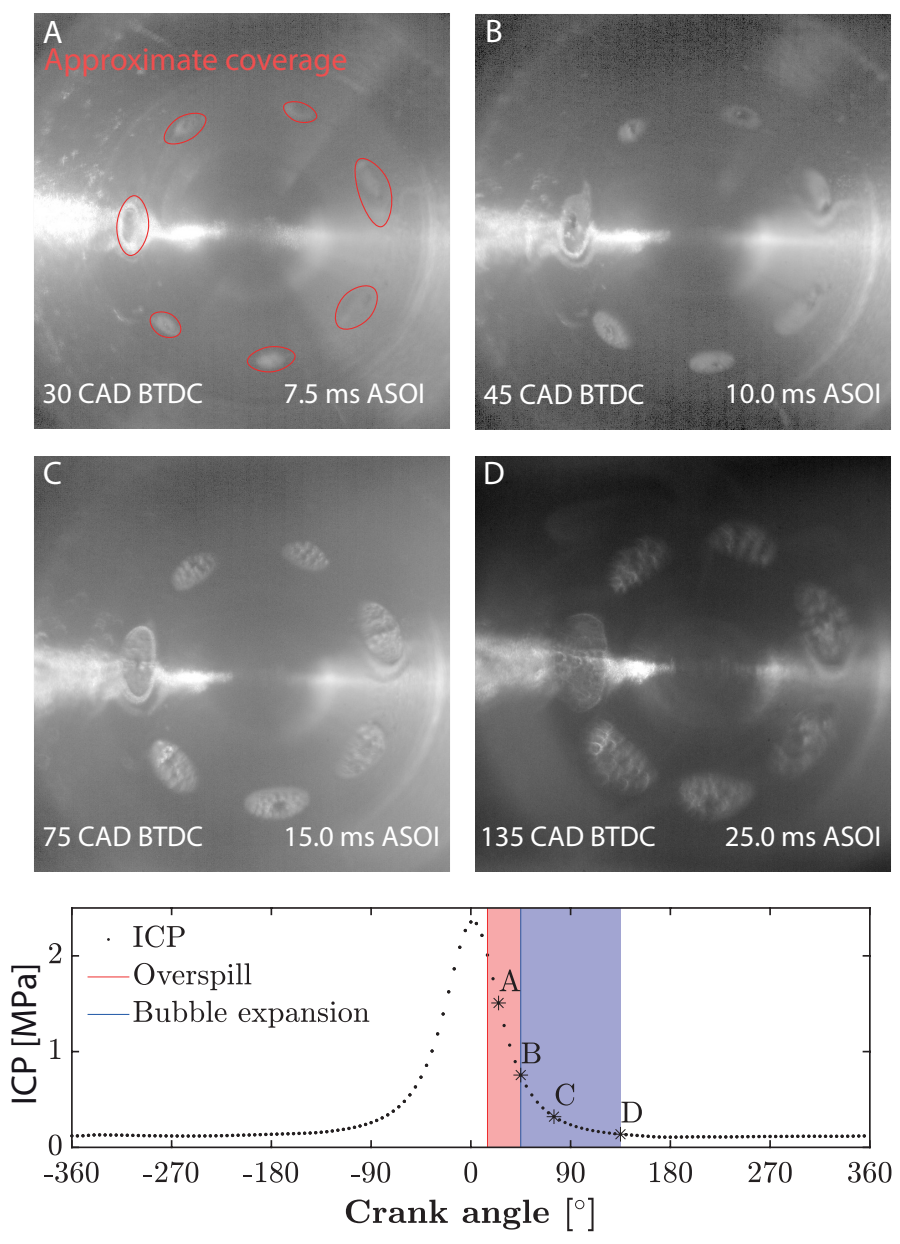

Figure 6: The injector nozzle surface and near-nozzle region throughout the expansion stroke. Red ovals mark the approximated coverage areas in insert A. An average pressure trace is given for an entire cycle. It highlights the period of overspill without identifiable bubble expansion by a red shaded region and the period of overspill with identifiable bubble expansion by a blue shaded region. The point in which each image was taken is given by stars combined with their associated letters.

It was hypothesised that the surface bubbling was due to the lighter components of the fuel boiling on the nozzle surface. To test this hypothesis the in-cylinder pressure and temperature were simulated as isentropic processes accounting for heat transfer and blow-by (Figure 7). The simulated and the measured pressures were matched by varying the thermal loss and blow-by coefficients whilst keeping them within a realistic range. The simulated variables are only plotted between intake valve closing and 
exhaust valve opening since the equations used are not applicable outside that range. An in-cylinder gas temperature (ICT) of $366 \mathrm{~K}$ was obtained at the initial time of potential boiling (when the fuel-vapour interfaces encapsulating the bubbles became distinguishable), acting across the vapour-liquid boundary. However, it is believed that boiling would be dictated by the nozzle temperature due to its high thermal conductivity. Although the approximated peak ICT is $439 \mathrm{~K}$ (still below the octane vapour saturation temperature at $45 \mathrm{CAD}$ ), the nozzle surface temperature would be much lower than this due to thermal inertia, the relatively short period of maximum ICT, and the engine head temperature of around $358 \mathrm{~K}[37,38]$. During a previous investigation we measured the nozzle tip temperature with an embedded K-type thermocouple inside a 6-hole Siemens VCO injector [27]. The experiments were carried out in a motored reciprocating rapid compression machine with an engine speed of $500 \mathrm{rpm}$. At a maximum ICP of $5 \mathrm{MPa}$ and a maximum in-cylinder gas temperature of approximately $650 \mathrm{~K}$, the nozzle tip temperature fluctuated between 407.0 and $408.6 \mathrm{~K}$ with an average of 407.6 K, plotted in Figure 7. The in-cylinder conditions were more conducive of elevated nozzle surface temperatures than those found here, indicating that the actual value in this experiment must be lower than $407.6 \mathrm{~K}$.

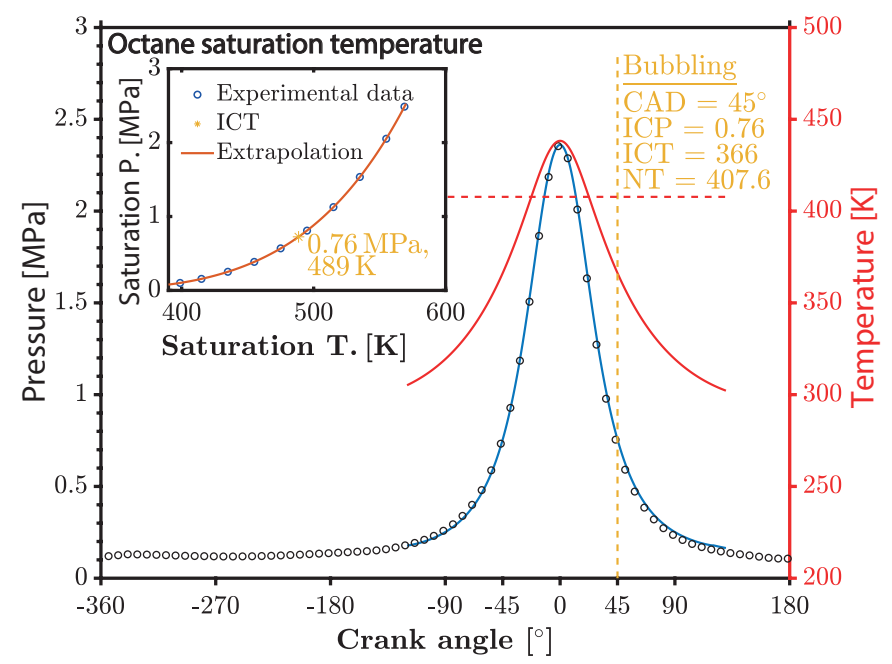

- Measured ICP — Simulated ICP — Simulated ICT---Nozzle Temperature

Figure 7: Scatter points give the measured ICP between -360 and $180 \mathrm{CAD}$. The simulated ICP is given with a solid blue curve and the simulated temperature with a solid red curve. An average nozzle surface temperature (NT), measured in a previous study under conditions more conducive of high nozzle tip temperatures [27], is given by a dashed red line. The conditions at $45 \mathrm{CAD}$ are highlighted using an orange vertical dashed line. The pressure at this point was cross-referenced in the second figure with the octane vapour saturation temperature curve.

The lightest, most volatile component in diesel (that has a mass fraction above trace) is octane with a mass fraction of around $0.3 \%$ in EN590 diesel [39]. Hence, it has been used here as an extreme case surrogate for diesel to find out if the surface bubbling is caused by boiling. A vapour saturation curve for octane is given in Figure 7 . The data points are taken from experimental results by Liley et al. [40] and the vapour saturation curve was found through polynomial extrapolation of the data points. The orange star highlights the temperature required for octane to boil at $0.76 \mathrm{MPa}$, the ICP at the initial time of potential boiling (45 CAD ATDC). A vapour saturation temperature of $489 \mathrm{~K}$ was found using the simulated data, significantly greater than the gas and surface temperatures discussed in the previous paragraph, refuting the hypothesis of boiling at this time.

Even though the result suggests that boiling is not the cause of the bubbling observed at 45 CAD ATDC, it also shows that boiling does occur later in the cycle. The large drop in ICT will reduce the vapour saturation temperature yet the decrease in nozzle surface temperature will be relatively small due to thermal inertia [37, 38]. Boiling may also occur within the nozzle before 45CAD ATDC due to the internal rarefaction caused by the EOI dribble reducing the vapour saturation temperature. Furthermore, the result does not reject the possibility of evaporation occurring at the liquid boundaries at 45 CAD ATDC, yet this would not induce the bubbling observed. Evaporation at the gas-liquid interface cannot induce bubbling since the phase change occurs at the gas-liquid interface, where it would not become encapsulate by fuel. Additionally, Bubbles precipitating through evaporation or boiling at the fuel-surface boundary would adhere to the surface, whereas the observed bubbles moved freely with the spreading fuel.

It is possible that the surface bubbling is caused by the expansion of gas trapped in surface crevices when the fuel film spreads, yet the visual inspection did not show any correlation between the coverage area and the volume of bubble-trapped gas. Therefore there are two possible surface bubbling mechanisms to be considered. First of all, there could be small vapour bubbles within the fuel prior to exiting the nozzle which expand as the in-cylinder pressure drops, supported by the reduced transparency of the initial overspill. Second, the bubbles form as a result of dissolved gasses precipitating out of the fuel.

\section{THE EXHAUST STROKE}

The bubble agglomerations grew to a maximum, unstable size shortly after the exhaust valves opened and the ICP dropped to near atmospheric (around 150 \pm 10 CAD ATDC, Figure $8 \mathrm{~A}$ ). They continuously collapsed until $-335 \mathrm{CAD}$ when only a few small bubbles remained on the nozzle surface (Figure 8D). Several collapse mechanisms were observed:

- A pressure wave was released from the collapse of a large bubble inducing instabilities in the surrounding bubble boundaries that result in their collapse. The collapsing bubbles also released pressure waves that collapsed their neighbouring bubbles. The pattern re- 
peated in large chain reactions until only very small, stable bubbles remained (Figure 8D).

- The gas flow pattern across the nozzle displaced the bubble agglomerations from their affiliated orifice towards the side of the nozzle closest to the exhaust valves (from orifices 1,2 and 3 towards orifices 7, 4 and 4 respectively). The agglomerations collided causing instabilities through either bubble collapse or coalescence, resulting in large chain reactions of collapsing bubbles.

- The bubbles in an agglomeration coalesced into one large unstable bubble that subsequently collapsed.

More than $15 \%$ of the agglomerations projected large droplets into the cylinder as they collapsed (between 1 and 5 droplets were visible). An example of this phenomena is shown in Figure 9 shortly after non-firing top dead centre (TDC). This example was selected due to the scattering of light by the piston bowl at this time increasing the illumination of the event, however the example is relatively late in the cycle with respect to the other occurrences. As the agglomeration collapsed the outer boundary was propelled along the surface in the form of a long ligament, subsequently breaking into droplets that were projected into the cylinder. The droplets frequently had a diameter larger than $100 \mu \mathrm{m}$ and in some cases they split to maintain stability. The airborne droplets were visibly drawn towards the exhaust valves, potentially contributing towards $\mathrm{UHC}$ emissions. However, if this phenomena still occurred in a firing engine, the droplet would most likely evaporate whilst air-borne due to the greater gas and exhaust temperatures.

Every occurrence of fuel projection is marked as a red dot on the ICP trace in Figure 8. There was no instances of fuel projection before bottom dead centre and it occurred most frequently between 180 and $270 \mathrm{CAD}$. The reason for this trend has not yet been confirmed, however it is speculated that the gas flow velocities in the immediate vicinity of the nozzle are at a maximum during this period due to the exhaust of the in-cylinder gas.

Despite the removal of fuel due to the bubble agglomeration collapse, a large amount of fuel still remained on the nozzle at 350 CAD BTDC (355 CAD BTDC being the intake stroke, Figure 8D). Unlike during the expansion stroke, the residing fuel was transparent indicating that it did not contain any small vapour bubbles. There are no signs of bubbling on the nozzle further disputing the hypothesis of boiling. The thermal inertia through the nozzle limits the variation of its surface temperature throughout the cycle and since the ICP is much lower at BDC, decreasing the vapour saturation temperature, boiling is more likely to occur at this time than at 45 CAD ATDC.

If the engine was not skip-fired, the majority of the events described in the previous 2 subsections may still occur, yet their time-scale would be much shorter due to the in-
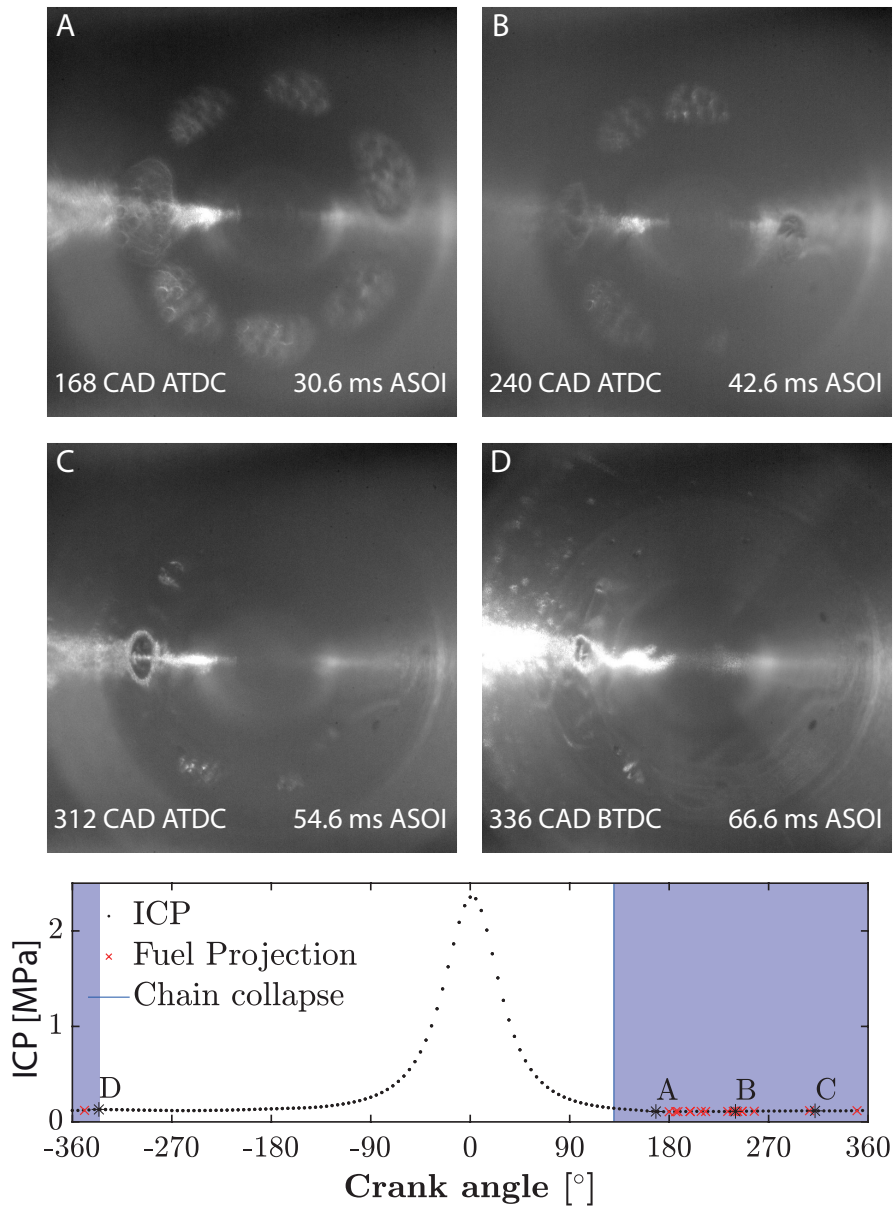

Figure 8: The injector nozzle surface and near-nozzle region throughout the exhaust stroke. Below the images the average pressure trace is given. It highlights the period that bubbles collapse in chain reactions by a blue shaded region and each instance of fuel projection due to these chain reactions with red crosses. The point in which each image was taken is given by their associated letters.

creased gas and nozzle temperatures. Immediately after the dribble event, the increased ICP and ICT would reduce the fuel's viscosity, conducive to more overspill through capillary action [41]. If orifice-trapped gas expansion is a major contributor towards the overspill, its rate and magnitude may also increase due to the higher ICT and temporal pressure differential. The greater nozzle surface temperature would relax the contact angle of the resulting nozzle-bound film and reduce the fuel-surface adhesion, leading to a higher spreading rate and a thinner film [41]. The large increase in pressure during the start of the expansion stroke (roughly TDC to 45CAD) would increase the vapour saturation temperature and inhibit instant vaporisation of the overspilling fuel, despite the greater surface temperature [40]. The pressure would subsequently drop at a much greater rate, yet the nozzle surface temperature would remain at its increased temperature due to the low thermal inertia throughout the nozzle [38]. Consequently, a higher rate of surface bubbling may arise, as well as rapid vaporisation through 

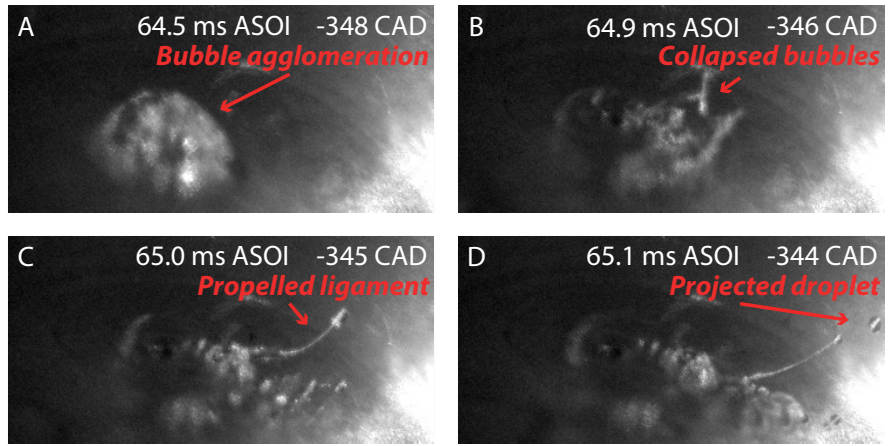

Figure 9: Images taken depicting the implosion of a bubble agglomeration, resulting in the projection of fuel into the cylinder. Each image is labelled with a letter and the timing is provided. The red text highlights the event of interest in each image.

both boiling and evaporation. The bubbles would have a reduced stability since the gas temperature would decrease the surface tension causing the larger bubbles to collapse, thus smaller bubble sizes would be expected [42]. Furthermore, the combustion may promote an increased near-nozzle gas flow that leads to additional bubble instabilities. The increased ICTs and ICPs due to combustion may not inhibit fuel projection through the collapse of bubble agglomerations, yet the event would occur at a much earlier stage in the cycle since the majority of the surface-bound fuel would have vaporised prior to the exhaust stroke. Any fuel released through the collapse of bubble agglomerations would evaporate whilst airborne due to the greater gas temperatures, therefore it is unlikely that any liquid fuel would exit the cylinder via the exhaust.

\section{THE INTAKE STROKE}

The majority of the surface-bound fuel was removed from the injector nozzle by high velocity in-cylinder gas passing across the injector surface (Figure 10D). Although most, if not all, of the surface-bound fuel in a firing engine would vaporise before intake valve opening [38, 40,43], any fuel in the cylinder at this time would have detrimental effects on the subsequent combustion event [44]. A main splashing event occurred at $208 \pm 2$ CAD BTDC in which a large proportion of the fuel was projected into the cylinder followed by several smaller splashing events over the proceeding 20 crank angles (Figure 10C). The only other time that the surface-bound fuel was significantly displaced during the intake stroke was between 320 and 305CAD BTDC (Figure 10A). The gas to liquid interface became rippled as the film spread towards orifice 7 , a similar direction to the subsequent fuel projection event, indicating a similar interaction with the in-cylinder gas flow (Figure 10).

The periods in which the two events took place are plotted against the in-cylinder pressure and the intake valve lift in Figure 10. A correlation with the ICP was not found, however the intake valve lift during the two periods significantly overlapped. Figure 11 shows the position of the
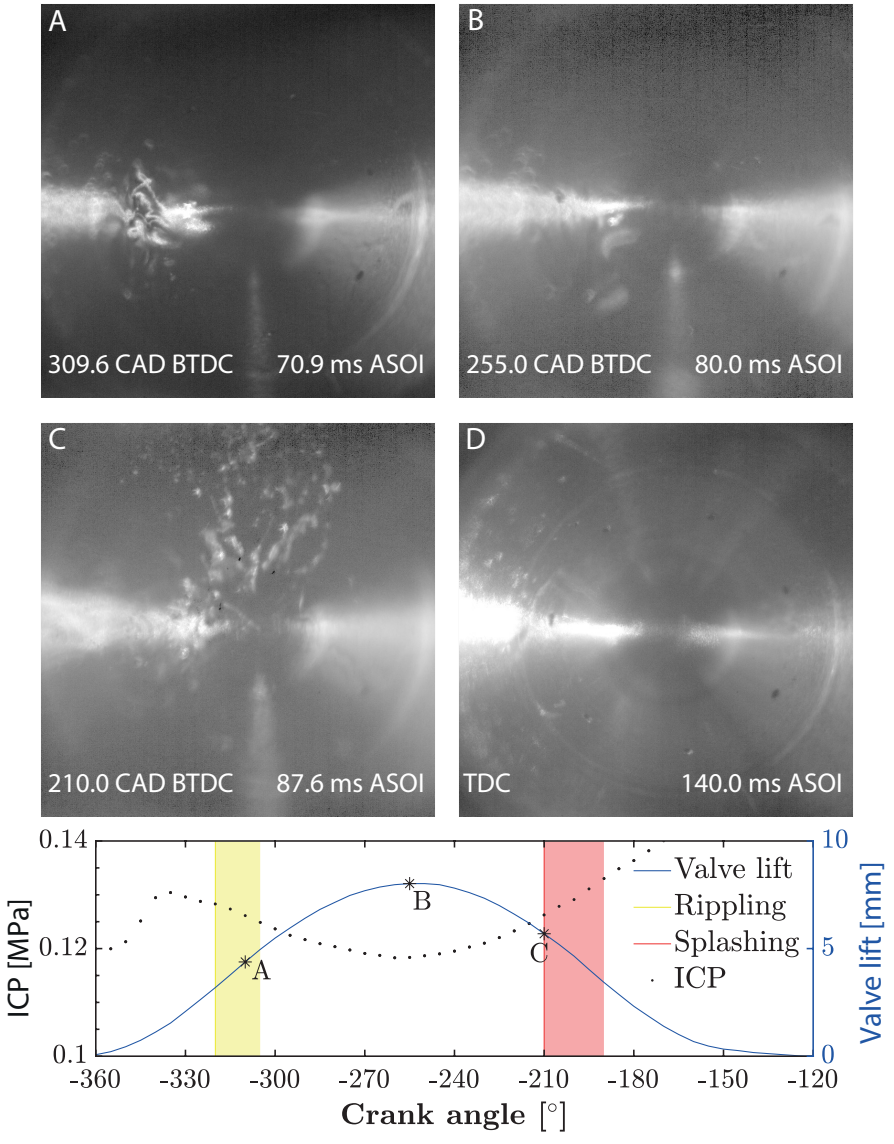

Figure 10: The injector nozzle surface and near-nozzle region throughout the intake and compression strokes. Below the images the average pressure trace is given with the intake lift plotted by a solid blue curve. It highlights the period that rippling of the surface film occurs and the period in which fuel is removed from the nozzle.

valves in relation to the nozzle. There was no airflow from the top right intake valve since the swirl manifold valve was fully closed, increasing the airflow velocities from the bottom intake valve. The arrows in the image highlight the direction of the intake flow entering the cylinder. The arrow that overlaps with the nozzle hole gives the direction of the flow that would interact with the nozzle surface, correlating with the direction of the fuel displacement. As the valve lifts and closes the local air velocity through the valve curtain changes and so does its primary direction into the chamber (across the Vertical plane, not depicted in Figure 11), hence it could wipe across the nozzle and displace the wetted area at similar valve lifts. It is likely that the small temporal difference in the events is due to the contrasting valve velocities. During valve closing, the increased intake velocities relative to the valve's motion would greatly increase the pressure gradient into the cylinder, therefore further increasing the flow velocity into the cylinder. This may explain why the splashing occurred during valve closing and not during valve opening. The valve lifting and closing velocities in addition to the intake flow rate would increase proportionally to the engine speed. This suggests that the effect of the interaction between the intake flow and nozzle surface would be much greater at increased piston velocities. 


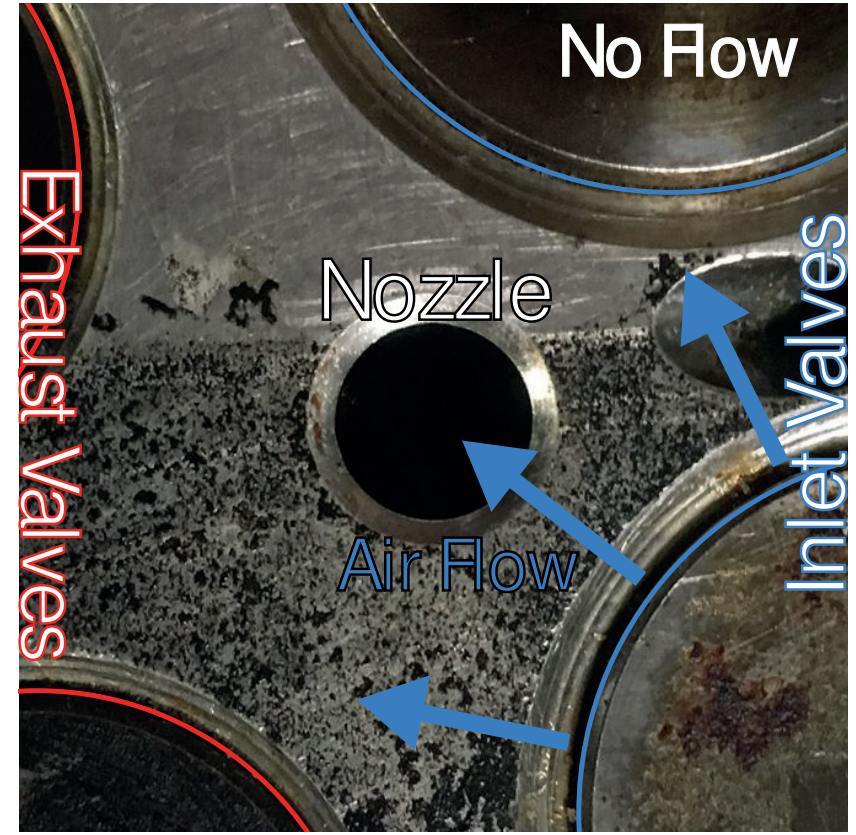

Figure 11: An image of the engine head, highlighting the nozzle and valve positions (injector not present). The intake valves are on the right of the injector hole and the exhaust valves are on the left. The diagonal hole between the intake valves is for a the glow plug. The blue arrows give the direction of the intake flow.

The intake air has a much lower temperature than the nozzle surface, therefore its interaction with the nozzle may result in a sudden drop in the temperature of both the surface and the surface-bound fuel. The temperature drop in a firing engine would be considerably greater and could effect the composition of a deposit on the nozzle surface. In the current investigation a VCO-type nozzle has been used for simplification of the processes observed, whereas the majority of modern passenger engines use sac type nozzles. The pressure differential across the nozzle during the splashing event may dislodge fuel residing in a sac causing it to overspill onto the opposing nozzle surface. The surface-bound fuel may remain until the subsequent combustion. If more fuel is uncontrollably removed from a sac type nozzle prior to the subsequent injection, the valve-opening and nozzle-refilling dynamics would change and may result in cycle-cycle variations.

\section{CONCLUSIONS}

High-speed visualisations at the microscopic scale were performed on a diesel injector nozzle within a motored DI engine under idling conditions. Several major near-nozzle and surface-bound phenomena were identified during the dribble event and post injection that potentially increase pollutant emissions and contribute towards the growth of carbonaceous deposits. The dependence of the observed behaviour on the non-reactive nature of the spray was discussed and the changes anticipated in the presence of combustion were described. The investigation led to the following conclusions:
- At the end of the injection event large droplets and ligaments were released into the cylinder. As the fuel was released from the orifice, a small volume of fuel adhered to the nozzle which retracted back resulting in surface wetting.

- Nozzle-residing fuel was dislodged by expanding gas and overspilled onto the external nozzle surface between 15 CAD ATDC and exhaust valve opening. The volume of overspilt fuel was considerably greater than the fuel that impinged on the surface during the dribble event.

- Bubbles formed, expanded and coalesced within the surface-bound fuel creating large bubble agglomerations. The hypothesis of the bubbling resulting from boiling at 45 CAD ATDC was refuted through consideration of octane's vapour saturation curve (octane being a surrogate for the lightest components within the hydro-carbon mix), combined with a comparison of the fuel film on the proceeding intake stroke.

- The bubble agglomerations collapsed in large chain reactions. In some cases the resulting pressure waves projected large droplets into the cylinder, visibly drawn towards the exhaust.

- As the intake valves closed, the intake air was diverted towards the nozzle, removing the remaining surface-bound fuel and projecting it as large liquid structures into the cylinder. It is unlikely that the fuel would be present on the injector surface in a fired engine at this time, however the implications of this process on nozzle surface temperature and sac injector late-cycle overspill are of great consequence.

It must be noted that these conclusions are only valid for VCO type nozzles within a motored engine. Further investigations will focus on fired conditions to create more realistic thermal boundary conditions, whilst the effects of nozzle type, injection pressure, intake induction pressure and fuel physical properties will be established.

\section{ACKNOWLEDGEMENTS}

This work was supported by the UK's Engineering and Physical Science Research Council [EPSRC grants EP/K020528/1 and EP/N509607/1] and BP international Ltd.

\section{REFERENCES}

[1] Dieselnet, EU cars and light trucks, in: Emission standards, ECOpoint inc, 2017.

[2] M. M. Rahman, K. M. Mohammed, R. A. Bakar, Effects of air-fuel ratio and engine speed on performance of hydrogen fueled port injection engine, Journal of Applied Sciences 9 (2009) 1128-1134. doi:10.3923/jas. 2009.1128.1134. 
[3] S. Matsumoto, K. Yamada, K. Date, Concepts and evolution of injector for common rail system, in: S. international (Ed.), SAE 2012 International Powertrains, Fuels and Lubricants Meeting, 2012. doi:10. 4271/2012-01-1753.

[4] Delphi DFI 21 diesel common rail injectors, Report, Delphi, 2017. URL: http: //delphi.com/manufacturers/cv/powertrain/ common-rail-systems/.

[5] J. Barker, P. Richards, M. Goodwin, J. Wooler, Influence of high injection pressure on diesel fuel stability: A study of resultant deposits, SAE International Journal of Fuels and Lubricants 2 (2009) 877-884. doi:10.4271/2009-01-1877.

[6] A. P. Watkinson, D. I. Wilson, Chemical reaction fouling: A review, Experimental Thermal and Fluid Science 14 (1997) 361-374. doi:10.1016/ S0894-1777 (96) 00138-0.

[7] A. Birgel, N. Ladommatos, P. Aleiferis, N. Milovanovic, P. Lacey, P. Richards, Investigations on deposit formation in the holes of diesel injector nozzles, SAE International Journal of Fuels and Lubricants 5 (2011) 123-131. doi:10.4271/2011-01-1924.

[8] P. Lacey, S. Gail, J. M. Kientz, G. Benoist, P. Downes, C. Daveau, Fuel quality and diesel injector deposits, SAE International Journal of Fuels and Lubricants 5 (2012) 1187-1198. doi:10.4271/2012-01-1693.

[9] R. Caprotti, A. Breakspear, O. Graupner, T. Klaua, Detergency requirements of future diesel injection systems, in: Powertrain and Fluid Systems Conference and Exhibition, SAE International, 2005. doi:10.4271/2005-01-3901.

[10] J. Reid, S. Cook, J. Barker, Internal injector deposits from sodium sources, SAE International Journal of Fuels and Lubricants 7 (2014) 436-444. doi:10. 4271/2014-01-1388.

[11] J. Barker, P. Richard, C. Snape, W. Meredith, Diesel injector deposits - an issue that has evolved with engine technology, in: SAE International Powertrains, Fuels and Lubricants Meeting, SAE International, 2011. doi:10.4271/2011-01-1923.

[12] A. Magno, E. Mancaruso, B. M. Vaglieco, S. Florio, G. Gioco, E. Rebesco, Study on spray injection and combustion of fouled and cleaned injectors by means of 2-D digital imaging in a transparent CR diesel engine, in: 11th International Conference on Engines and Vehicles, SAE International, 2013. doi:10.4271/2013-24-0062.

[13] R. Cracknell, R. Wardle, R. Pos, L. Ganippa, Effect of diesel injector tip deposits on transient spray behavior, Internationaler Motorenkongress, 2016. doi:10. 1007/978-3-658-12918-7_13.
[14] R. Caprotti, N. Bhatti, G. Balfour, Deposit control in modern diesel fuel injection systems, SAE International Journal of Fuels and Lubricants 3 (2010) 901915. doi:10.4271/2010-01-2250.

[15] N. J. Rounthwaite, R. Williams, C. Mcgivery, J. Jiang, F. Giulliani, B. Britton, A chemical and morphological study of diesel injector nozzle deposits - insights into their formation and growth mechanisms, SAE International Journal of Fuels and Lubricants 10 (2017) 106-114. doi:10.4271/2017-01-0798.

[16] J. Tang, S. Pischinger, M. Lamping, T. Krfer, M. Tatur, D. Tomazic, Coking phenomena in nozzle orifices of DI-diesel engines, SAE Int. J. Fuels Lubr. 2 (2009) 259-272. doi:10.4271/2009-01-0837.

[17] Z. Stepien, The reasons and adverse effect of diesel injector deposit formation, Combustion engines 156 (2014) 20-29.

[18] P. A. Risberg, S. Alfredsson, The effect of zinc and other metal carboxylates on nozzle fouling, in: SAE 2016 World Congress and Exhibition, SAE International, 2016. doi:10.4271/2016-01-0837.

[19] S. Rakshit, High Speed Flow Simulation in Fuel Injector Nozzles, Master of science in mechanical engineering, 2012. URL: https://scholarworks. umass . edu/theses/942/.

[20] D. Li, Y. Kang, X. Ding, X. Wang, Z. Fang, Effects of nozzle inner surface roughness on the performance of self-resonating cavitating waterjets under different ambient pressures, Journal of Mechanical Engineering 63 (2017) 92-102. doi:10.5545/sv-jme.2016. 3563.

[21] H. K. Suh, C. S. Lee, Effect of cavitation in nozzle orifice on the diesel fuel atomization characteristics, International Journal of Heat and Fluid Flow 29 (2008) 1001-1009. doi:10.1016/j . ijheatfluidflow. 2008.03.014.

[22] J. Barker, S. Cook, P. Richards, Sodium contamination of diesel fuel, its interaction with fuel additives and the resultant effects on filter plugging and injector fouling, SAE International Journal of Fuels and Lubricants 6 (2013) 826-838. doi:10.4271/ 2013-01-2687.

[23] N. J. Barsic, A. L. Humke, Performance and emissions characteristics of a naturally aspirated diesel engine with vegetable oil fuels, in: SAE International Congress and Exposition, SAE International, 1981. doi:10.4271/810262.

[24] D. Li, Y. Kang, X. Wang, X. Ding, Z. Fang, Effects of nozzle inner surface roughness on the cavitation erosion characteristics of high speed submerged jets, Experimental Thermal and Fluid Science 74 (2016) 444-452. doi:10.1016/j.expthermflusci. 2016.01 .009 . 
[25] C. P. Koci, A. Dempsey, J. Nudd, B. Knier, Understanding hydrocarbon emissions in heavy duty diesel engines combining experimental and computational methods, SAE International Journal of Engines 10 (2017) 1093-1109. doi:10.4271/2017-01-0703.

[26] J. E. Turner, V. Stetsyuk, C. Crua, R. J. Pearson, M. R. Gold, The effect of operating conditions on post-injection fuel discharge in an optical engine, in: 13th Triennial International Conference on Liquid Atomization and Spray Systems, 2015. URL: https: //iclass2015.tw/index.php.

[27] J. Turner, D. Sykes, G. D. Sercey, V. Stetsyuk, M. Gold, R. Pearson, C. Crua, A quantitative analysis of nozzle surface bound fuel for diesel injectors, in: ILASS 2017 - 28th European Conference on Liquid Atomization and Spray Systems, 2017. doi:10.4995/ILASS2017.2017.4661.

[28] R. Pos, M. Avulapati, R. Wardle, R. Cracknell, T. Megaritis, L. Ganippa, Combustion of ligaments and droplets expelled after the end of injection in a multi-hole diesel injector, Fuel 197 (2017) 459-466. doi:10.1016/j.fuel.2017.02.048.

[29] C. Crua, M. R. Heikal, M. R. Gold, Microscopic imaging of the initial stage of diesel spray formation, Fuel 157 (2015) 140-150. doi:10.1016/j.fuel . 2015. 04 . 041.

[30] A. B. Swantek, D. Duke, F. Z. Tilocco, N. Sovis, C. F. Powell, A. L. Kastengren, End of injection, mass expulsion behaviors in single hole diesel fuel injectors, in: ILASS Americas 26th Annual Conference on Liquid Atomization and Spray Systems, 2014. URL: http://www.ilass.org/2/index.html.

[31] A. B. Swantek, A. L. Kastengren, D. Duke, F. Z. Tilocco, N. Sovis, C. F. Powell, A further examination of fuel dribble from single hole diesel nozzles, in: ILASS Europe 26th Annual Conference, 2014. URL: http://ilasseurope.org/ events/26th-ilass-europe-2014/.

[32] S. Moon, W. Huang, Z. Li, J. Wang, End-of-injection fuel dribble of multi-hole diesel injector: Comprehensive investigation of phenomenon and discussion on control strategy, Applied Energy 179 (2016) 7-16. doi:10.1016/j. apenergy.2016.06.116.

[33] W. E. Eagle, M. P. B. Musculus, Cinema-stereo imaging of fuel dribble after the end of injection in an optical heavy-duty diesel engine, in: UPV (Ed.), THIESEL 2014 Conference on Thermo- and Fluid Dynamic Processes in Direct Injection Engines, 2014. URL: $10.1177 / 1468087414560307$.

[34] R. Lockett, M. Jeshani, K. Makri, R. Price, An optical characterization of atomization in non-evaporating diesel sprays, in: SAE World Congress and Exhibition, SAE International, 2016. doi:10.4271/ 2016-01-0865.
[35] V. Kirsch, M. A. Reddemann, J. Palmer, R. Kneer, Zooming into primary breakup mechanisms of highpressure automotive sprays, in: ILASSEurope: Conference on Liquid Atomization and Spray Systems, 2017. doi:10.4995/ILASS2017.2017.4603.

[36] M. Battistoni, Q. Xue, S. Som, Large-eddy simulation (les) of spray transients: Start and end of injection phenomena, Oil Gas Sci. Technol. Rev. IFP Energies nouvelles 71 (2016) 4. doi:10.2516/ogst/ 2015024.

[37] S. Anantharaman, M. Baskaran, A research on factors affecting nozzle tip temperature in diesel engines, SAE International, 2015. doi:doi.org/10. 4271/2015-01-2791.

[38] R. Leuthel, M. Pfitzner, M. Frobenius, Numerical study of thermal-fluid-interaction in a diesel fuel injector, SAE International, 2008. doi:10.4271/ 2008-01-2760.

[39] S. S. Sazhin, M. A. Qubeissi, R. Nasiri, V. M. Gunko, A. E. Elwardany, F. Lemoine, F. Grisch, M. R. Heikal, A multi-dimensional quasi-discrete model for the analysis of diesel fuel droplet heating and evaporation, Fuel 129 (2014) 238-266. doi:10.1016/j . fuel.2014.03.028.

[40] P. E. Liley, G. F. Hewitt, C. F. Beaton, Physical property data for the design engineer, New York: Hemisphere Pub. Corp, 1989.

[41] D. Bonn, J. Eggers, J. Indekeu, J. Meunier, E. Rolley, Wetting and spreading, Reviews of Modern Physics 81 (2009) 739-805. doi:10.1103/RevModPhys.81. 739.

[42] C. Brennen, Cavitation and Bubble Dynamics, volume 44, 1995. doi:10.1017/CB09781107338760.

[43] C. P. Koci, Y. Ra, R. Krieger, M. Andrie, D. E. Foster, R. M. Siewert, R. P. Durrett, Multiple-event fuel injection investigations in a highly-dilute diesel low temperature combustion regime, SAE International Journal of Engines 2 (2009) 837-857. doi:10.4271/ 2009-01-0925.

[44] J. Zhu, O. A. Kuti, K. Nishida, Effects of injection pressure and ambient gas density on fuel - ambient gas mixing and combustion characteristics of d.i. diesel spray, SAE International, 2011. doi:10.4271/ 2011-01-1819. 